\title{
EuroGentest NoE, the ESHG, and genetic services
}

\author{
Jean-Jacques Cassiman \\ European Journal of Human Genetics (2017) 25, S47-S49; doi:10.1038/ejhg.2017.155
}

The history of the European Society of Human Genetics, described in detail in other contributions, showed that the society started in 1967 as a meeting place for clinical geneticists but gradually evolved into an organisation bringing together scientists interested in exchanging results of their research. Clinical geneticists and cytogeneticists started to feel that they were losing their informal exchanges about clinical experiences at these meetings. Soon this led some of them to set up separate associations, such as the European Society of Human Reproduction and Embryology (ESHRE) in 1985, and in 1997 the European Cytogenetics Association (ECA).

In the meantime, the results of genome research were providing increasing diagnostic possibilities to clinical genetic facilities. The activities of existing molecular genetic labs grew steadily and more and more labs started to incorporate a molecular approach in their research and diagnostic activities. With the financial support of national initiatives, or EU programmes (Framework Programmes, FP4-7) such as gene mapping efforts, EuroGEM, Genethon, CEPH, different CF projects pertaining to lab quality in particular the $\mathrm{CF}$ Quality Network, EMQN, CRMGEN and many others, molecular labs and clinical services became aware of a number of quality issues that required a European consensus approach in order to maintain the highest quality possible in their services to the community.

Indeed, results from different surveys and quality assessments showed that genetic services in Europe, while based on high-quality scientific know-how, suffered from technical errors and poor reporting, caused by a lack of structuring and complementarity at the European level, and the absence of a common European objective to provide quality services to all its consumers. Diverse and heterogeneous quality schemes, lack of reference systems and differing Member State (MS) regulations, added to the overall disorganization and fragmentation of services. In the meantime, genetic services faced an ever-increasing number of requests for testing, while widespread susceptibility testing and pharmacogenetic tests were entering clinical practice.

During exchanges between molecular and clinical geneticists involved in many of these EU-supported initiatives a consensus grew about the need for a European initiative. In June 2002, together with the precious support of the Joint Research Center IPTS of the EU Commission (in particular Dolores Ibarreta), in
Seville, a letter of intent was drafted with the support of 28 European genetic facilities and organisations. It was sent to DG Research in an attempt to convince the Commission to include a topic on the quality of genetic testing in the next Framework Programme call (FP6). Favorable comments reached us about this letter, and preparations for a full proposal started in the second part of 2003 and continued in 2004. They further crystallised the view of many participants on what needed to be done. The FP6 program finally provided the opportunity to submit proposals for Networks of Excellence (NoE) that could run for five years. With the active help in writing of many interested geneticists, patient organisations and SMEs, a proposal was submitted to DG Research in 2004, with a budget of 10000000 Euro.

The contract with the EU commission for EUROGENTEST NoE (2005-2010), Genetic testing in Europe Network for test development, harmonisation, validation and standardisation of services, with 34 official partners, was signed at the end of 2004. A list of active participants and collaborators is in box 1 .

The EuroGentest NoE (EUGT) aimed to develop the necessary infrastructure, tools, resources, guidelines and procedures leading to the establishment of harmonised, quality genetic testing services in Europe, which can interact with, stand as a model for, or help to achieve similar services on other continents. This was to be achieved by bringing together, in a real long-term partnership, experts and expert centres in Europe engaged in different aspects of testing, including researchers, small and medium enterprises (SMEs), testing laboratories, quality management and public health experts, ethicists, lawyers, sociologists, educational authorities and consumers. The NoE focused on four major domains: quality of the laboratories, quality of the clinical aspects of the genetic services, translation of technologies into diagnostic practice and educational aspects.

The NoE also set up an Advisory Board with representatives of European and international organisations in order to have wide input from all sectors (see box 2).

During the 5 years hundreds of interested parties (labs, facilities, non-EU organisations, etc) joined the $\mathrm{NoE}$ as associate members. Through the many official and associated participants the NoE soon became a network of networks with representatives of a large number of organisations interested in its aims such as: ECA, Orphanet, 
EMQN, ERNDIM, OECD, CDC, ACMG, WHO, EFB, Europabio, EDMA, GeneBanC, SAFE NoE, RELAGH, PHGEN, CAPABILITY, EUROCARE CF, CANGENETEST. This not only stimulated the activities of the NoE, but also helped to spread its message, develop information and provide support to large numbers of genetic facilities including those present on different continents. Terms such as accreditation, ISO norms, and evaluation soon came to be understood by the whole genetics community in Europe.

Over the 5 years of the NoE, the different WPs and Units achieved their milestones and deliverables and already many achievements were clearly visible. To mention just a few:

- EQAs for molecular (EMQN; CF Network) and biochemical tests (ERNDIM) have been given support allowing them to expand their activities more than 500 laboratories are involved.

- A new electronic EQA for cytogenetics (CEQA) was set up and became very successful.

- 27 very successful training sessions about quality management and accreditation have been organised in different countries for 400 participants from 39 different countries.

- Reference materials for Prader Willi, Fragile X and Bcl-ABL have been developed and were adopted by WHO.

- Different meetings pertaining to RF and the IVD directive led to a proposal for modification of the directive.

- A European Central database of laboratories with validated quality criteria has been developed in collaboration with Orphanet and is online on the Orphanet website.

- Validation of the Chemagen DNA extractor, MLPA and HR-MCA methods have been finalised and published.

- Approved minimal criteria for quality genetic counseling have been published.

- A tool for self-evaluation for clinical geneticists has been developed.

- A contextual definition of genetic testing is available.

- 33 Gene cards containing information on the clinical utility of genetic test are available.

- A database containing information on 20 important diagnostic gene patents has been developed.

- The overview of 27 MS on the implementation of the European Convention on Human Rights and Biomedicine has published results on $15 \mathrm{MS}$ and has created a very successful website with this information.

- 15 informative leaflets on aspects of genetics for patients are available and have been translated in 27 languages.

- The document 'Core competences in Genetics for Health Professionals in Europe' has been approved by the genetics community and published.

- A series of publications on 'Genetic testing of minors' based on EU surveys is available.

- A new network of European genetic counselors was launched.

- 32 fellowships for young investigators to spend a short training period in the lab of a NoE participant were provided.

- EuroGentest participated in different expert meetings at the EU, US and global level.

- Many participants in EuroGentest gave presentations at numerous $\mathrm{EU}$ and international congresses.
- Newsletters were published, the website was overhauled a number of times, press releases were drafted, numerous scientific publications were submitted.

- More than 140 international publications have been produced.

Since participants and interacting scientists were members of the ESHG, during the whole duration of the NoE, quality meetings were held and special sessions on technological developments were organised at the ESHG annual meetings. To further integrate the philosophy of EUGT in the activities of the society, a special quality committee was created by the society in 2007, and its role in improving the quality of the clinical and laboratory aspects of the genetic services were discussed in this committee. As a result of the discussions in the NoE and in the society committee it also became clear that the ESHG should invest in creating a structure that could monitor and improve the quality of the training of professionals involved in providing the genetic services (clinical, lab geneticists, and counsellors). This led to the creation of an ESHG committee for professional aspects and resulted in 2012 in the creation of the European Board of Medical Genetics EBMG).

When the EUGT contract ended in 2010 we were able to conclude that international awareness of existing quality issues had been improved. The will to make these necessary improvements and to move towards harmonisation was now present both within and outside the NoE. Many tools necessary to make these improvements were now available. Clearly, EuroGentest had become a kind of trade mark for quality issues in genetic services.

Since prolongation or the resubmission of a proposal for a $\mathrm{NoE}$ under FP7 was not possible, different solutions with the potential to continue some activities were examined. The board of the ESHG, while being very interested in the EUGT activities, was understandably somewhat reluctant to take over all its activities in view of the annual budget of $€ 1000000$ that had supported the network thus far. Finally, a proposal for a Concerted Action submitted by Gert Matthijs, who had succeeded Jean-Jacques Cassiman, was successful and allowed the continuation of some of the activities of EuroGentest from January 2011 onwards.

In the meantime other EU-funded projects pertaining to molecular genetic activities, such as TechGene and 3 Gb-Test, were running and led to the development of various guidelines and best practice recommendations published in the EJHG. SOPs and lab accreditation became a must for diagnostic labs. The existence of External Quality Assessment and the harmonisation of the tests being offered became evident. An ad hoc group of ESHG Board members reviewed what EUGT had achieved in order to find approaches that would allow ways to integrate EuroGentest activities into the society. A proposal to undertake this without the risk of bankruptcy was made to the board. Finally, in 2013 a new committee was created by the board the ESHG-EuroGentest Committee. This committee includes four sub-committees representing the main activities of the original EuroGentest NoE. I am convinced that all the geneticists in Europe or further afield who contributed to or participated in EuroGentest, will continue, together with the ESHG, to support the approach initially developed by the NoE and its successors in order that the provision of quality genetic services to the population can be guaranteed. 
Box 1: Eurogentest participants and collaborators

Jean-Jacques Cassiman, co-ordinator, Gert Matthijs, Univ Leuven; Antoon Vyverman/ Alain Denis, Enthoven Associates Design Consultants NV; Elisabeth Dequeker, Leuven; Michael Morris, Geneva University Hospitals; Joris Vermeesh, Leuven; Rob Elles, University Hospitals NHS Trust, Manchester; Clemens R. Muller, University of Wuerzburg; György Fekete, Semmelweis University of Medicine, Budaprest; Michal Witt, Intern. Inst. Molec. and Cell Biology, Warschau; Milan Macek, Charles University Prague; David Barton, National University of Ireland, Dublin; David Gancberg, IRMM, Geel; Rosalind Hastings, Oxford Radcliffe Hospitals NHS Trust, Oxford; Brian Fowler, University's Childrens Hospital Basel; Ségolène Aymé, INSERM, Paris, Bert Bakker, Leiden University Medical Center; Guillermo Antiñolo, Hospitales Universitarios Virgen del Rocio, Seville; Maj Hultèn, University of Warwick, Coventry; Peter Chedraui, Universidad Catolica de Santiago de Guayaquil; Peter Rosseel, Management Consulting and Research Leuven; David Atlan, PhenoSystems SA, Bois de Villers; Bruno Dallapiccola, Istituto C.S.S. Mendel, Roma; Andrew Devereau; University Hospitals NHS Trust, Manchester; Domenico Coviello, Instituti Clinici di Perfezionamento, Milano; Ulf Kristoffersson, University Hospital, Lund; Helena Kääriäinen, University of Turku; Jörg Schmidtke,Hannover Medical School; Lauren Kerzin-Storrar, CMMC Manchester; Jorge Sequeiros, IBMC, University Porto; Guillermo Antiñolo, Hospitales Universitarios Virgen del Rocio, Seville; Dragica Radojkovic, Institute Molecular Genetics, Belgrade; Irma Nippert, Westfälische Wilhelms Universität, Münster; Herman Nys, University of Leuven; Kris Dierickx, University of Leuven; Alastair Kent, The Genetic Interest Group, London; Bert Bakker, Leiden University Medical Center; Geertrui Van Overwalle, University of Leuven; Jan Schouten, MRC-Holland, Amsterdam; Jürgen Oster, Chemagen Biopolymer, Aachen; Beverly Searle, UNIQUE, Caterham, UK.
Box 2: Eurogentest Scientific Advisory board

Domenica Taruscio, National Center for Rare Diseases, Erik Tambuyzer, Chair Ethics committee, EuropaBio, Christine Tarrajat EDMA, David Bennett EFB (European federation of Biotechnology), Elettra Ronchi OECD, Joe Boone, PHPPO/CDC, Laboratory systems, USA, Koen De Bakker, General Manager Catholic University Leuven, Marc Delpech, Hopital Cochin, Farndon Peter, UK Network on Genetic Testing UK, Carolyn Sue Richards, American College Medical Genetics, USA, Victor Boulyenkowv WHO, Pier Franco Pignatti, Liaison officer ESHG, Claus Bartram, National societies human genetics representative, Grzegorz Wegrzyn, Chair of CEE-GN (Central Europe and Eastern countries Genetic network) Hori Tomoshige, Director Science and technology planning, Japan.

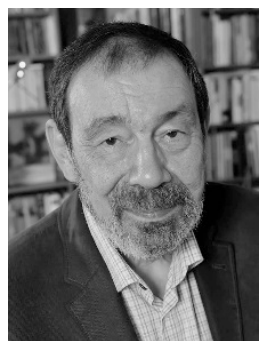

Jean-Jacques Cassiman

A biography of this author appears earlier in this issue. 